Original Research

\title{
Pharmacists' perception of their role during COVID-19: a qualitative content analysis of posts on Facebook pharmacy groups in Jordan
}

\author{
Tareq L. MUKATTASH ${ }^{(D)}$, Anan S. JARAB (D), Ibrahim MUKATTASH, Mohammad B. NUSAIR \\ Rana ABU FARHA (D), May BISHARAT, Iman A. BASHETI (D). \\ $\begin{array}{lll}\text { Received (first version): 7-Apr-2020 Accepted: 12-Jul-2020 Published online: 31-Jul-2020 } & \end{array}$
}

\begin{abstract}
Objective: This study aimed to evaluate the content available on Facebook pharmacy groups in Jordan regarding the perception of the pharmacists' role during the coronavirus pandemic in Jordan.

Methods: Researchers identified Facebook pharmacy groups through the search engine on the Facebook website. The main search keywords were pharmacy, pharmacist, pharmacists, and Jordan using both Arabic and English. Two researchers analyzed the posts and discussion threads on local pharmacy Facebook groups in a period between March $20^{\text {th }}$ and April $3^{\text {rd }}$. A total of 184 posts and threads were identified for the purpose of the study.

Results: Identified threads and responses resulted in three overarching themes: pharmacists having a positive role during the pandemic, taking additional responsibilities and services, and having passive or negative roles. A positive role was seen in pharmacists acting as first-line healthcare providers, creating public's awareness regarding COVID-19, and being responsible for chronic medication refill during the pandemic. Taking additional responsibilities was summarized in home deliveries and involvement in industrial and corporate efforts to deal with the pandemic. A passive/negative role was seen mostly among hospital pharmacists not being proactive during the pandemic and by pharmacists trying to maximize profits during pandemic time.

Conclusions: Pharmacists perceived their role as a positive role during the coronavirus pandemic. Not only they took responsibilities for their daily services during the crises, but they took additional responsibilities to assure patient safety and satisfaction.
\end{abstract}

\section{Keywords}

Pharmacists; Pharmaceutical Services; Pharmacies; Severe Acute Respiratory Syndrome; Coronavirus; Pandemics; Professional Role; Self Concept; Personal Satisfaction; Social Media; Qualitative Research; Jordan

\section{INTRODUCTION}

Coronavirus Disease 2019 (COVID-19) caused by the novel coronavirus (SARS-CoV-2) is a condition that emerged in Wuhan city and disseminated outstandingly, affecting many countries around the world in a short period of time, in an uncontrollable way. ${ }^{1-3}$ As a consequence to this serious outstanding situation, the World Health Organization (WHO) declared this viral outbreak to be a Public Health Emergency of International Concern on the $30^{\text {th }}$ January $2020{ }^{4}$ Soon after, the WHO classified COVID-19 as a pandemic infectious disease on 11 March $2020 .{ }^{5,6}$ As of $2^{\text {nd }}$ April 2020, the total number of confirmed cases exceeded $1,010,000$ cases in over 180 countries, resulting in over

Tareq L. MUKATTASH. PhD. Department of Clinical Pharmacy, Faculty of Pharmacy, Jordan University of Science and Technology. Irbid (Jordan). tlmukattash@just.edu.jo

Anan S. JARAB. PhD. Department of Clinical Pharmacy, Faculty of Pharmacy, Jordan University of Science and Technology. Irbid (Jordan). asjarab@just.edu.jo

Ibrahim MUKATTASH. MA, PGCert, PhD. Department of Marketing, Faculty of Business Administration, Applied Science Private University. Amman (Jordan). i mukattash@asu.edu.jo

Mohammad B. NUSAIR. MSc PhD. Department of Pharmacy Practice, Faculty of Pharmacy, Yarmouk University. Irbid (Jordan). nusair@yu.edu.jo

Rana ABU FARHA. MSc, PhD. Department of Clinical Pharmacy and Therapeutics, Faculty of Pharmacy, Applied Science Private University. Amman (Jordan). r abufarha@asu.edu.jo

May BISHARAT. MBBS, MSc, FRCS. Department of Urology, Grea Ormond Street Hospital. London (United Kingdom).

dr.mai.bisharat@gmail.com

Iman A. BASHETI. PhD. Department of Clinical Pharmacy and

Therapeutics, Faculty of Pharmacy, Applied Science Private

University. Amman (Jordan).dr_iman@asu.edu.jo

\section{2,800 deaths. $^{7}$}

There is also strong evidence that this novel virus can be transmitted by people with mild symptoms, presymptomatic or even asymptomatic. ${ }^{8}$ Most infected SARSCoV-2 patients reported clinical symptoms ranging from mild symptoms such as fever, dry cough, fatigue, shortness of breath and muscle pain to severe acute respiratory distress syndrome. ${ }^{9}$ such as dry cough, sore throat, and fever. Several cases have been resolved spontaneously. Nevertheless, some fatal complications have occurred, including organ failure, septic shock, pulmonary edema, and, extreme pneumonia. ${ }^{10}$ Also, patients with COVID-19 are at increased risk of developing cardiovascular complications including venous thromboembolism, dysrhythmias, acute heart failure, and acute myocardial infarction. ${ }^{11-15}$

This requires a collaborative teamwork by all healthcare professionals to support in controlling this scenario. ${ }^{2}$ Pharmacists worldwide are integral part within the healthcare system, and since the emergence of this viral outbreak they have experienced a challenging situation and hard time like never before. They are currently working in the frontline with other healthcare providers in fighting the battle of COVID-19 outbreak, and they are undertaking everything they can do to support their patients in all possible areas. This role of pharmacists was supported by the declaration of the updated International Pharmaceutical Federation (FIP) guideline for pharmacists all around the world on the $19^{\text {th }}$ of March $2020{ }^{16}$ The aim 
of this guideline was to guide pharmacists in community, hospital and clinical biology on COVID-19 pandemic. ${ }^{16}$ The guideline documented several recommendations to deal with COVID-19 viral outbreak, among them the interventions and patient counselling that should be provided by pharmacists during this serious situation. ${ }^{16}$

One noticeable question that stands up here is whether pharmacists in Jordan could have responsibilities in counteracting this COVID-19 outbreak efficiently and what are their perception regarding their contributing roles. To assess that, it was difficult for us as researchers to conduct structured interviews with pharmacists because of the quarantine imposed on all citizens in Jordan. Hence, social network content analysis for pharmacists' posts on various local pharmacy groups was performed. This quantitative content analysis aimed to measure frequencies and informative analysis of Jordanian pharmacists' Facebook posts to assess their perception about their role and responsibilities in dealing with this COVID-19 pandemic. It is thought that exploring pharmacists' perception about their role during the pandemic would help facilitate and increase their contribution along with other healthcare professionals and support them to deliver optimal services.

\section{METHODS}

\section{Sample}

Facebook represents a vast and unbiased source of information, posts on Facebook are believed to be bias free and represent members' honest opinions making them optimal for social and qualitative research. ${ }^{17,18}$ Hence, it was adopted for the present study to evaluate the content that is available on Facebook pharmacy groups regarding pharmacists' perception of their role during the COVID-19 pandemic in Jordan.

Researchers identified Facebook pharmacy groups through the search engine on the Facebook website. The main search keywords were pharmacy, pharmacist, pharmacists, and Jordan using both Arabic and English. The inclusion criteria included active groups that clearly stated being pharmacy groups in Jordan, active groups for working pharmacists, active groups with a clear location as Jordan, groups that at least had 100 members. The exclusion criteria were Facebook groups that did not have recent activities during the last 30 days, pharmacy students' groups, and groups that had pharmacists from outside
Jordan, and groups that had commercial purposes. Ten groups were identified and a requested to join the selected groups was placed. A list and description of the groups selected for the study purposes are present in Table 1. Both public and private Facebook groups were sought for the study's purpose. Although private groups are visible in Facebook search, only the group's name and member list are visible on the group's main page. Content posted on the group's Timeline is visible on a members-only basis. The opposite is true for public groups.

Threads and post that included a discussion related to pharmacists' role and duties during the COVID-19 pandemic were included in the study. Threads and posts that discussed irrelevant pharmacist duties during the pandemic were excluded. Two independent researchers identified and analyzed relevant threads and posts posted on local pharmacy Facebook groups in a period between March $20^{\text {th }}$ and April $3^{\text {rd }} 2020$. This resulted in a total of 184 posts and threads identified across all ten Facebook groups.

The research protocol was reviewed and approved by the Institutional Review Board at the King Abdulla University Hospital/ Jordan University of Science and Technology (REF: 2020228).

\section{Analysis}

A generic qualitative approach was chosen to get a better understanding of pharmacists' reports of their subjective opinions, attitudes, and beliefs. The majority of posts and comments were in Arabic. For reporting purposes, responses were translated from Arabic to English and back translated from English to Arabic to ensure that the context and meaning has not changed. Posts by respondents were edited on a limited basis to remove content that did not convey meaning (repeated words, stutters, etc.) and to correct for grammar. An ellipsis mark was used to note removal of such extraneous content. Square brackets were used in quotations to supply words omitted by participants or to replace sensitive information. All responses were copied and de-identified prior to analysis and later imported into QSR International's NVivo v11 Software.

The thematic analysis was preformed following a generic qualitative approach and the thematic analysis steps described by Braun and Clarke. ${ }^{19,20}$ Two researchers independently read through the previously identified threads to get a general sense of the data and become familiar with it. The two researchers independently labeled

\begin{tabular}{|l|l|r|r|l|}
\hline \multicolumn{1}{|c|}{ Table 1. Facebook pharmacy groups analyzed } & Active since & $\begin{array}{c}\text { Number of } \\
\text { members }\end{array}$ & Status & \\
\hline Jordanian Pharmacists Association - JPA & Jun 2018 & 1,119 & Private & https://www.facebook.com/groups/404805126665582 \\
\hline JUST Pharmacy Alumni & May 2017 & 4,218 & Private & $\underline{\text { https://www.facebook.com/groups/13690688866473005/ }}$ \\
\hline Pharmacy Group & May 2016 & 1,023 & Public & https://www.facebook.com/groups/1753891778182245/ \\
\hline Pharmacy Activities & Nov 2009 & 1,399 & Public & $\underline{\text { https://www.facebook.com/groups/190711086836/ }}$ \\
\hline Pharmacist and proud & Jul 2013 & 1,559 & Public & $\underline{\text { https://www.facebook.com/groups/1393511454196634/ }}$ \\
\hline Pharmacy & Feb 2015 & 31,478 & Private & https://www.facebook.com/groups/933170873373269 \\
\hline Irbid PharmacoFamily & Feb 2019 & 1,470 & Private & https://www.facebook.com/groups/1968190656636999/ \\
\hline Jordan Pharmacist* & May 2018 & 13,892 & Private & https://www.facebook.com/groups/2142688405959087/ \\
\hline $\begin{array}{l}\text { Pharmacists of the Hashemite Kingdom } \\
\text { of Jordan* }\end{array}$ & May 2018 & 4,882 & Public & https://www.facebook.com/groups/2067851230153445/ \\
\hline Jordan Pharmacist* & May 2013 & 2,549 & Private & https://www.facebook.com/groups/138056589713165/ \\
\hline * Group name translated from Arabic & & & \\
\hline
\end{tabular}


phrases in the entire threads related to the research questions and assigned codes to theses labels and described them. These codes were collated into themes and subthemes through an interactive process between the two researchers and discrepancies were resolved by consensus.

\section{RESULTS}

Ten Facebook pharmacy groups were identified for the purpose of the present study. Those included a total of 63,589 participants and were a mix of private (6) and public (4) groups visible to all Facebook users. Further details are present in Table 1. A total of 184 posts and threads were identified across all ten Facebook groups and were analyzed for the purpose of this study.

Qualitative analysis revealed three overarching themes with regards to the perception of pharmacists regarding their role during the COVID-19 virus outbreak in Jordan. The emerging themes were: playing positive roles, taking additional responsibilities and services, and playing passive/negative roles. Emerging themes are summarized and in Table 2.
The first theme was playing a positive role. Many posts and threads discussed the positive role the pharmacists played before and during the COVID-19 outbreak. Three sub themes emerged from this theme and those were: Pharmacists acted as first-line health providers, role in creating public awareness role, and continuing chronic medication refills. It was discussed that pharmacists acted as first line health care provides along with other healthcare professionals who worked effectively during COVID-19 outbreak. Post also discussed that the pharmacists' role during the outbreak reduced the pressure on hospitals and allowed them to focus on more critical cases that needed serious medical attention. Pharmacists highly valued this role and were proud of their contribution during this period. Another important role perceived by pharmacists in their Facebook posts was their role in creating and spreading public awareness regarding COVID19 risk factors and prevention. Pharmacist encouraged each other to use social media outlets to spread awareness and to fight wrong beliefs. It was also mentioned that they did face-to-face counselling to customers. It was also reported that pharmacists worked on preparing chronic medications refills as they felt obliged to supply patients

Table 2. Summary of themes generating from the analysis of posts

\begin{tabular}{|c|c|c|}
\hline Overarching themes & Sub-themes & Selected posts \\
\hline \multirow[t]{3}{*}{$\begin{array}{l}\text { Positive perceived } \\
\text { roles } \\
(n=126)\end{array}$} & $\begin{array}{l}\text { First-line health } \\
\text { provider } \\
\text { (n=109) }\end{array}$ & $\begin{array}{l}\text { - "We have relieved part of the burden on hospitals and emergency departments, and this has } \\
\text { allowed hospitals to focus on the serious cases that need critical care." } \\
\text { - "Pharmacists are still working during the outbreak and dealing with patients. We deal with less } \\
\text { serious cases and give patients the necessary medications without them needing to go to } \\
\text { hospital, which has helped relieve part of the burden on hospitals in circumstances like these." }\end{array}$ \\
\hline & $\begin{array}{l}\text { Public awareness } \\
\text { role } \\
(\mathrm{n}=97)\end{array}$ & $\begin{array}{l}\text { - "a small number of pharmacists have shown initiative or created videos and social media } \\
\text { campaigns to spread awareness." } \\
\text { - "We are constantly spreading awareness about the virus and how important it is for people } \\
\text { with symptoms to get tested. We are continuously educating people on the ways of prevention } \\
\text { and trying to prevent patients from panic buying medications and hand sanitizer. We also have } \\
\text { to deal with patients taking preventive medications that they've heard about on the T.V. but } \\
\text { which are still under research or even medications which could lead to several complications." }\end{array}$ \\
\hline & $\begin{array}{l}\text { Chronic } \\
\text { medication refills } \\
(n=83)\end{array}$ & $\begin{array}{l}\text { - "Pharmacists are refilling medications for chronic conditions, and working to deliver } \\
\text { medications to patients where possible." } \\
\text { - "pharmacists in medical centers and community pharmacies are going through patients' } \\
\text { profiles and making refills for chronic conditions" }\end{array}$ \\
\hline \multirow{2}{*}{$\begin{array}{l}\text { Additional } \\
\text { responsibilities and } \\
\text { services } \\
(\mathrm{n}=117)\end{array}$} & $\begin{array}{l}\text { Medicine Home } \\
\text { delivery } \\
(n=103)\end{array}$ & $\begin{array}{l}\text { - "During the outbreak, pharmacists have been personally delivering medication to people's } \\
\text { homes without charging for delivery, even though the profit made from selling medication is } \\
\text { very limited." }\end{array}$ \\
\hline & $\begin{array}{l}\text { Involvement in } \\
\text { industrial and } \\
\text { corporate } \\
(\mathrm{n}=71)\end{array}$ & $\begin{array}{l}\text { - Let's not forget the main role of pharmacists during this pandemic, which has been to } \\
\text { manufacture medications. I would particularly like to mention the role of pharmacists working } \\
\text { in pharmaceuticals, who have worked hard and conducted much research with doctors in } \\
\text { order to supply the market with medication to treat Covid-19. }\end{array}$ \\
\hline \multirow[t]{2}{*}{$\begin{array}{l}\text { Passive/Negative } \\
\text { perceived roles } \\
(\mathrm{n}=79)\end{array}$} & $\begin{array}{l}\text { Insufficient role } \\
\text { in hospitals } \\
(n=63)\end{array}$ & $\begin{array}{l}\text { - The role of pharmacists during the outbreak has been significant but also limited. Clinical } \\
\text { pharmacists should be in hospitals providing treatment because that is their field of expertise. } \\
\text { This pandemic has revealed just how unfair the medical sector is towards the role of clinical } \\
\text { pharmacists. } \\
\text { - "In circumstances like these, we should be seeing clinical pharmacists in hospitals, providing } \\
\text { treatment to patients. The fact that our role has been limited to working in community } \\
\text { pharmacies has been very demotivating. " }\end{array}$ \\
\hline & $\begin{array}{l}\text { Practice aiming } \\
\text { for more profit } \\
(n=54)\end{array}$ & $\begin{array}{l}\text { - "In my opinion, pharmacists should be doing a lot more, as the role of many of them has been } \\
\text { solely commercial and has been aimed at serving the financial interests of the pharmacists } \\
\text { themselves. This explains why many of them have been calling for permits to allow them to } \\
\text { open their pharmacies under the curfew" } \\
\text { - "community pharmacists on Facebook groups have been acting selfishly and serving their own } \\
\text { interests only." } \\
\text { - "It really is disheartening for me to have to say this, but unfortunately, the role of a large } \\
\text { number of pharmacists has been solely commercial. I've heard pharmacists' multiple times } \\
\text { saying things like "I'm not a delivery person" or "do you expect me to go out just to deliver } \\
\text { some baby milk?". }\end{array}$ \\
\hline
\end{tabular}


https://doi.org/10.18549/PharmPract.2020.3.1900

with their medications regardless of the expected risk during the viral outbreak. Pharmacists reported that they have taken all the possible precautions and that they could not withhold treatment from people at need and guarantee its supply. One pharmacist had written that offering their services at this time is part of their obligation to the oath they took after graduation.

The second theme was taking additional responsibilities and services. Many threads posted by pharmacists focused on taking additional responsibilities that they do not normally do during normal practice days. Two sub themes emerged from this theme and those were: Medicine Home delivery and involvement in industrial and corporate work. Many pharmacists wrote about personally delivering medicines to patients. This point particularly received a lot of discussion and pharmacists reported positive perceptions of this service as home delivery of medicines is not allowed in Jordan usually. However, some pharmacists thought that it was not the pharmacists' role to deliver medicines in person and using a courier service would have been more suitable. This was responded to by many posts that the courier would not be able to counsel patients and assure optimal use of treatment. Further roles were being active in the drug industry business. Pharmacists discussed that many of those working in pharmaceutical industry had to work extra hours to make sure that the strategic inventory of medicines was not depleted, especially that the imports were affected with travel ban and flight restrictions internationally. Those working in drug stores discussed that they had to supply the market with more products such as Vitamin C, gloves, hand sanitizer, antiseptics, facemasks, and many other products needed during the pandemic. In general pharmacists perceived those roles as a health obligation and were satisfied to play this role in such a hard time.

The third theme was playing passive/negative roles. Some pharmacists were not satisfied with their roles during the pandemic and thought that their role was not enough if compared to other healthcare professionals fighting the spread of the disease on frontlines. Sub themes emerging from this theme were: Insufficient role in hospitals and practice aiming for more profit. Pharmacists perceived their role in hospitals as insufficient. It was discussed that the majority of pharmacists working in hospitals did not have direct contact with patients and their role was only to dispense medicines, check prescriptions, and prepare refills for delivery. Pharmacists' posts on Facebook groups indicated that pharmacists had aimed for a greater role, especially clinical pharmacists who would have an effective role in managing the treatments of patients with COVID-19, specifically those with multiple morbidities. Pharmacists believed that their role was limited in hospitals and hoped for more effective roles in the future. It was also discussed that a minority of pharmacy owners took advantage of the pandemic and patients in need to make extra profit and charge more for drugs and products. Though it was reported that such practices were limited, it was thought that they will reflect a negative image on all the pharmacy sector in the country.

\section{DISCUSSION}

The present study sheds light on pharmacists' perception of their role during the coronavirus pandemic in Jordan. Since the beginning of the pandemic internationally researchers started investigating different aspects of this novel disease. As the available peer reviewed literature regarding the role of healthcare professionals during this pandemic is scarce, the role of pharmacist has not been studied yet. Understanding how pharmacist contributed during the pandemic would highlight their achievements and would also expose any gap in their practice giving ample opportunity for future enhancement.

Internationally, pharmacists are in the frontline in the fight against the novel coronavirus disease (COVID-19) and they are doing everything in their power to support their patients, including in areas currently in lockdown. ${ }^{21}$ In the present study pharmacists perceived their role as a positive role and integral along with other healthcare professionals. Regardless of the risk pharmacists could face they continued offering their services during the pandemic. ${ }^{22}$ In Jordan pharmacists act as first line healthcare professionals and due their accessible nature patients tend to refer to the pharmacy before any other healthcare professional. ${ }^{23,24}$ It is obvious from this study that pharmacists maintained their practices to serve the community. Important roles, along with their ability to create public awareness about COVID-19, were prevention procedures, risk factors, and signs and symptoms. This role depends on pharmacists having the sufficient knowledge and information regarding the emerging disease. This could be done through online courses managed by the Ministry of Health, Jordan Food and Drug Administration, and the Jordan Pharmacists' Association, which will help the pharmacist to fulfil this role. The Jordan Pharmacists' Associated has launched "Hello Pharmacist" app and a hotline during the COVID-19 pandemic. This service aimed to connect patients with pharmacists to answer their questions and to increase their accessibility to medicine. Moreover, pharmacists in Jordan have launched several campaigns over the social to increase awareness about COVID-19 prevention. Similarly, a multicultural project initiative led by PharmD students translated coronavirus guidelines for America into 23 languages. This initiative was a clear example of the global impact pharmacists can make to provide timely and highquality information to patients. ${ }^{25}$ This altogether, sets an example for the ability of pharmacists in spreading public awareness during the pandemic resulting in better adherence to social distancing and sanitization guidelines, hence slowing the infection rate among citizens.

In addition to their daily responsibilities, pharmacists had been involved in home delivery of medicines. ${ }^{26}$ Though this service is not allowed in Jordan, pharmacies have been allowed to deliver medicines to customers during the curfew period. ${ }^{24}$ Pharmacist who volunteered to work during the crises were issued daily permits to open their pharmacies and personally deliver medicines. This was to allow pharmacists deliver their full services of dispensing and counselling; hence no courier service was adopted. Home delivery of medicines has been proven to be a valuable service and it helps reducing treatment related problems especially in elderly and patients and those 

COVID-19: a qualitative content analysis of posts on Facebook pharmacy groups in Jordan. Pharmacy Practice 2020 Jul-

suffering from chronic ailments. ${ }^{27}$ This was specifically important in patients who were prescribed chronic medications and were dispensed monthly refills. Pharmacists had prepared and delivered those refills to ensure the supply of medications to those patients and guarantee treatment outcomes. ${ }^{28}$

On the other hand, pharmacists were not satisfied with their role in the hospital. It has been discussed that hospital pharmacists did not have any additional role to offer and did not have any contact with COVID-19 patients. This could be due to safety issues, reducing the number of healthcare professional at the risk of infection to the minimum. Furthermore, no roles for clinical pharmacists existed which could be also for similar reasons. According to FIP, hospital pharmacists need to provide several health and pharmaceutical services in collaborations with other health care providers to COVID-19 patients. Such service may have a significance effect in improving the selection of patients' drug therapy, and improving patient's overall health and outcomes. ${ }^{29}$ However, details about such pharmaceutical care is still lacking, and need to be urgently established. A recent study suggests that pharmaceutical care provided by hospital pharmacists for hospitalized COVID-19 patients in China was exceptional. The presence of hospital pharmacists in the healthcare team improve COVID-19 patients' outcome and reduce mortality. ${ }^{30}$ Still, the role of clinical pharmacists in hospitals is still not clear in the health system in Jordan and is restricted to education rather than intervention. ${ }^{31}$

Unfortunately, it was reported that some pharmacy owners took advantage of the situation and tried to make extra profits. This would be illegal as medicine prices in Jordan are regulated and the same in all pharmacies around the country. ${ }^{32}$ Medicines are priced before being granted a marketing authorization by the pricing committee at the
Jordan Food and drug Administration. ${ }^{33}$ Any change of this price has legal consequences and a financial fine. Pharmacy owners are obliged to abide by the rules and the delivery of their service during the pandemic is considered a national obligation. No healthcare professional should take advantage of citizen whatever the circumstances were. As pharmacist could be facing more risks working during the pandemic, a reduction in licensing fees or taxes could be offered by the government after the pandemic as an incentive. $^{34}$ It is however important to deliver pharmaceutical services during the pandemic insuring patient welfare and optimal outcomes. This interest should be the main driver for pharmacy owners and pharmacists regardless of the circumstances.

\section{CONCLUSIONS}

Overall, Jordanian pharmacists perceived to have positive role during the coronavirus pandemic. Pharmacists' role was not limited to their routine daily services during the crises, but they took additional responsibilities to assure patient safety, satisfaction, and accessibility to medicine. There is, however, a clear opportunity to engage hospital pharmacists in hospitals to provide pharmaceutical care services to COVID-19 hospitalized patients.

\section{CONFLICT OF INTEREST}

None.

\section{FUNDING}

The study was funded by the Deanship of Research at Jordan University of Science and Technology.

\section{References}

1. Huang C, Wang Y, Li X, Ren L, Zhao J, Hu Y, Zhang L, Fan G, Xu J, Gu X, Cheng Z, Yu T, Xia J, Wei Y, Wu W, Xie X, Yin W, Li H, Liu M, Xiao Y, Gao H, Guo L, Xie J, Wang G, Jiang R, Gao Z, Jin Q, Wang J, Cao B. Clinical features of patients infected with 2019 novel coronavirus in Wuhan, China [published correction appears in Lancet. 2020 Jan 30;:]. Lancet. 2020;395(10223):497-506. https://doi.org/10.1016/s0140-6736(20)30183-5

2. Kandel N, Chungong S, Omaar A, Xing J. Health security capacities in the context of COVID-19 outbreak: an analysis of International Health Regulations annual report data from 182 countries. Lancet. 2020;395(10229):1047-1053. https://doi.org/10.1016/s0140-6736(20)30553-5

3. Chen J, Qi T, Liu L, et al. Clinical progression of patients with COVID-19 in Shanghai, China. J Infect. 2020;80(5):e1-e6. https://doi.org/10.1016/i.jinf.2020.03.004

4. Eurosurveillance Editorial Team. Note from the editors: World Health Organization declares novel coronavirus (2019nCoV) sixth public health emergency of international concern. Eurosurveillance. 2020;25(5):200131e.

5. World Health Organization. Coronavirus 2020. Available at: https://www.who.int/health-topics/coronavirus\#tab=tab 1 (accessed Mar 22, 2020).

6. Centers for Disease Control and $P^{\wedge}$ revention. Coronavirus(COVID-19)-Situation summary. Available at: https://www.cdc.gov/coronavirus/2019-ncov/cases-updates/summary.html (accessed Mar 22, 2020).

7. Johns Hopkins University. Coronavirus COVID-19 Global Cases by the Center for Systems Science and Engineering (CSSE) at Johns Hopkins University. Available at: https://systems.jhu.edu/ (accessed Mar 22, 2020).

8. Hoehl S, et al. Evidence of SARS-CoV-2 Infection in Returning Travelers from Wuhan, China. N Engl J Med. 2020;382(13):1278-1280. https://doi.org/10.1056/nejmc2001899

9. Chen N, Zhou M, Dong X, Qu J, Gong F, Han Y, Qiu Y, Wang J, Liu Y, Wei Y, Xia J, Yu T, Zhang X, Zhang L. Epidemiological and clinical characteristics of 99 cases of 2019 novel coronavirus pneumonia in Wuhan, China: a descriptive study. Lancet. 2020;395(10223):507-513. https://doi.org/10.1016/s0140-6736(20)30211-7

10. Chen T, Wu D, Chen H, Yan W, Yang D, Chen G, Ma K, Xu D, Yu H, Wang H, Wang T, Guo W, Chen J, Ding C, Zhang X, Huang J, Han M, Li S, Luo X, Zhao J, Ning Q. Clinical characteristics of 113 deceased patients with coronavirus disease 
Mukattash TL, Jarab AS, Mukattash I, Nusair MB, Abu Farha R, Bisharat M, Basheti IA. Pharmacists' perception of their role during COVID-19: a qualitative content analysis of posts on Facebook pharmacy groups in Jordan. Pharmacy Practice 2020 JulSep;18(3):1900.

https://doi.org/10.18549/PharmPract.2020.3.1900 2019: retrospective study [published correction appears in BMJ. 2020 Mar 31;368:m1295]. BMJ. 2020;368:m1091.. https://doi.org/10.1136/bmi.m1091

11. Xie Y, Wang X, Yang P, Zhang S. COVID-19 complicated by acute pulmonary embolism. Radiol Cardiothorac Imaging. 2020;2(2):e200067. https://doi.org/10.1148/ryct.2020200067

12. Danzi GB, Loffi M, Galeazzi G, Gherbesi E. Acute pulmonary embolism and COVID-19 pneumonia: a random association?. Eur Heart J. 2020;41(19):1858. https://doi.org/10.1093/eurheartj/ehaa254

13. Driggin E, Madhavan MV, Bikdeli B, Chuich T, Laracy J, Biondi-Zoccai G, Brown TS, Der Nigoghossian C, Zidar DA Haythe J, Brodie D, Beckman JA, Kirtane AJ, Stone GW, Krumholz HM, Parikh SA. Cardiovascular Considerations for Patients, Health Care Workers, and Health Systems During the COVID-19 Pandemic. J Am Coll Cardiol. 2020;75(18):2352-2371. https://doi.org/10.1016/i.jacc.2020.03.031

14. Zhou $P$, et al. A pneumonia outbreak associated with a new coronavirus of probable bat origin. Nature. 2020;579(7798):270-273. https://doi.org/10.1038/s41586-020-2012-7

15. Welt FGP, Shah PB, Aronow HD, Bortnick AE, Henry TD, Sherwood MW, Young MN, Davidson LJ, Kadavath S, Mahmud E, Kirtane AJ; American College of Cardiology's Interventional Council and the Society for Cardiovascular Angiography and Interventions. Catheterization Laboratory Considerations During the Coronavirus (COVID-19) Pandemic: From the ACC's Interventional Council and SCAI. J Am Coll Cardiol. 2020;75(18):2372-2375. https://doi.org/10.1016/j.jacc.2020.03.021

16. FIP. FIP releases substantial update to COVID-19 guidelines for pharmacists around the world. Available at: https://www.fip.org/press-releases?press=item\&press-item=70 (accessed Mar 22, 2020).

17. Cole-Lewis H, Perotte A, Galica K, Dreyer L, Griffith C, Schwarz M, Yun C, Patrick H, Coa K, Augustson E. Social Network Behavior and Engagement Within a Smoking Cessation Facebook Page. J Med Internet Res. 2016;18(8):e205. Published 2016 Aug 2. https://doi.org/10.2196/jmir.5574

18. Snelson CL. Qualitative and mixed methods social media research: A review of the literature. Int J Qual Methods. 2016;15(1):1609406915624574. https://doi.org/10.1177\%2F1609406915624574

19. Caelli K, Ray L, Mill J. 'Clear as mud': toward greater clarity in generic qualitative research. Int J Qual Methods. 2003;2(2):1-13. https://doi.org/10.1177\%2F160940690300200201

20. Braun V, Clarke V. Using thematic analysis in psychology. Qual Res Psychol. 2006;3(2):77-101.

21. PGPUE. Community pharmacists in the frontline in the fight against the novel coronavirus disease (COVID-19). Available at: https://www.pgeu.eu/publications/press-release-community-pharmacists-in-the-frontline-in-the-fight-against-the-novelcorona-virus-disease-covid-19/ (accessed Mar 22, 2020).

22. CDC. Considerations for Pharmacies during the COVID-19 Pandemic. Available at: https://stacks.cdc.gov/view/cdc/86949/cdc 86949 DS1.pdf? (accessed Mar 22, 2020).

23. Mukattash TL, Bazzi NH, Nuseir KQ, Jarab AS, Abu-Farha RK, Khdour MR. Pharmaceutical care in community pharmacies in Jordan: a public survey. Pharm Pract (Granada). 2018;16(2):1126. https://doi.org/10.18549/pharmpract.2018.02.1126

24. Nazer LH, Tuffaha H. Health Care and Pharmacy Practice in Jordan. Can J Hosp Pharm. 2017;70(2):150-155. https://doi.org/10.4212/cjhp.v70i2.1649

25. Doroudgar S, Hernandez FE, Kali-Rai R, Yoshizuka K. Multi-Cultural Project Initiative: An inclusive representation of "Coronavirus Guidelines for America". Res Social Adm Pharm. 2020. [Ahead of Print]. https://doi.org/10.1016/i.sapharm.2020.04.006

26. Mukattash TL, Jarab AS, Abu-Farha RK, Nusair M, Basheti I, Mukattash IL, Obeidat RM, Khdour M. Willingness and Readiness to test for COVID-19; A qualitative exploration of community pharmacists. Int J Clin Pract. 2020. [Ahead of Print]. https://doi.org/10.1111/ijcp.13620

27. Basheti IA, Al-Qudah RA, Obeidat NM, Bulatova NR. Home medication management review in outpatients with chronic diseases in Jordan: a randomized control trial. Int J Clin Pharm. 2016;38(2):404-413. https://doi.org/10.1007/s11096-016$\underline{0266-9}$

28. Basheti IA, Nassar R, Barakat M, Alqudah R, Abufarha R, Mukattash TL, Saini B. Pharmacists' readiness to deal with the coronavirus pandemic: Assessing awareness and perception of roles. Res Social Adm Pharm. 2020. [Ahead of Print]. https://doi.org/10.1016/j.sapharm.2020.04.020

29. International Pharmaceutical Federation. Coronavirus SARS-CoV-2/COVID-19 Pandemic: information and interim guidelines for pharmacists and the pharmacy workforce. The Hague: FIP; 2020.

30. Song Z, Hu Y, Zheng S, Yang L, Zhao R. Hospital pharmacists' pharmaceutical care for hospitalized patients with COVID19: Recommendations and guidance from clinical experience. Res Social Adm Pharm. 2020. [Ahead of Print]. https://doi.org/10.1016/i.sapharm.2020.03.027

31. Hammad EA, Qudah RA, Akour AA. The impact of clinical pharmacists in improving Jordanian patients' health outcomes. Saudi Med J. 2017;38(11):1077-1089. https://doi.org/10.15537/smj.2017.11.21453

32. Abbott RB, Bader R, Bajjali L, Abu EISamen T, Obeidat T, Sboul H, Shwayat M, Alabbadi I. The price of medicines in Jordan: the cost of trade-based intellectual property. J Generic Med. 2012;9(2):75-85. https://doi.org/10.1177\%2F1741134312447499

33. Hammad E, Obeidat H, Hadidi I, Batarseh S, Al-Efan Q. The role of cost-effectiveness studies in Drug pricing decisions: a case review from Jordan. Value Health. 2015;18(3):A73. https://doi.org/10.1016/j.jval.2015.03.428

34. Houle SK, Grindrod KA, Chatterley T, Tsuyuki RT. Paying pharmacists for patient care: A systematic review of remunerated pharmacy clinical care services. Can Pharm J (Ott). 2014;147(4):209-232. https://doi.org/10.1177/1715163514536678 